\title{
A Case Study of American and Chinese College Students' Motivation Differences in Online Learning Environment
}

\author{
Chunjuan Zhao ${ }^{1} \&$ Zongxiang $\mathrm{Mei}^{2}$ \\ ${ }^{1}$ School of Foreign Languages, Shandong Normal University, Jinan, China \\ ${ }^{2}$ Confucius Institute at Central Connecticut State University, New Britain, Connecticut, USA \\ Correspondence: Chunjuan Zhao, No. 88 East Wenhua Road, School of Foreign Languages, Shandong Normal \\ University, Jinan, Shandong, China. Tel: 1-860-357-7645. E-mail: bluebird4020@163.com
}

\author{
Received: June 12, 2016 \\ Accepted: July 31, 2016 \\ Online Published: August 30, 2016 \\ doi:10.5539/jel.v5n4p104 \\ URL: http://dx.doi.org/10.5539/jel.v5n4p104
}

\begin{abstract}
Motivating students has been a key challenge facing instructors in non-face-to-face instructional contexts. Existing researches into motivation in online learning environment have revealed that there are learning motivation differences among students from different cultural backgrounds. The purpose of this study is to identify whether American and Chinese online learners' motivation differ in online learning environment and what characteristics of learners could exert influence on their motivation. This study, based on a survey of 162 students from West Virginia University and 210 students from Fudan University, China, revealed that there was a significant learning motivation difference between American and Chinese online learners. And it was also found that online learners' learning motivation were affected by such learners' characteristics as gender, employment status and marital status.
\end{abstract}

Keywords: online learning, online environment, learning motivation, motivation difference

\section{Introduction}

The last few years have witnessed a continual integration of information technologies into higher education. The Internet and other Information and Communication Technologies (ICTs) have facilitated online learning to develop into the most economical and feasible mode of expanding access to quality higher education (Stephen $\&$ Hui, 2009). Several universities have built Network Education/Distance Learning/E-learning College to provide more methods and choices for learning by computer through an intranet or the Internet. With this trend, there appear many studies about learner motivation with online learning. Some researchers have even identified cultural motivation differences between learners from different cultural contexts. Lim (2004) was one of those researchers. He did a comparative study between Korean and American online learners to identify how they perceived online learning motivation differently and what learner characteristics and cultural factors affected the online learner's learning motivation. His findings not only revealed that there was a significant difference in learning motivation between American and Korean online learners, but also found out that there were both group level and individual level characteristics that affected online learning motivation.

The purpose of this study is to identify if there also exist learning motivation differences between Chinese and American online learners, what these differences are and what learner characteristics contribute to these differences. The research hypothesis is:

H0: There is no difference in motivation between Chinese and American cultural background for online learning.

H1: Chinese online learners' score of learning motivation is significantly higher or lower than American online learners'.

\section{Literature Review}

\subsection{Online Learning}

As learning technology and its related fields continue to evolve, practitioners and researchers still have yet reached a consensus on the definition of online learning. Most researchers have described online learning as access to learning experiences by using certain type of technology (Benson, 2002; Conrad, 2002; Carliner, 2004). Hiltz and Turoff (2005) makes a clear statement that online learning is a newer version or, and improved version 
8of distance learning. In this sense, both pure online courses delivered entirely over the Internet, and hybrid or blended learning which combines traditional face-to-face instruction with learning over the Internet or learning facilitated by other technologies (Bliuc, Goodyear, \& Ellis, 2007; Hoic-Bozic, Mornar, \& Boticki, 2009), should all be considered as online learning. Therefore, following the above researchers, this paper takes the term of "online learning" as almost any learning environment in which electronic media such as computers are used as a component of an instructional delivery system.

Compared with traditional face-to-face learning, the benefits of online learning definitely go far beyond just being convenient and economical. It enables learners to self-direct or self-regulate individual learning, offers learners more flexibility and more accessibility to knowledge and skills in various formats and different regions. (Gratton-Lavoie \& Stanley, 2009; De la Varre, Keane, \& Irvin, 2011; Lorenzetti, 2013; Koller \& Ng, 2014). However, online learning instructors and learning designers are also facing numerous challenges, one of which is to keep students continually motivated.

\subsection{Motivation}

\subsubsection{Cultural Differences on Motivation}

Motivation by definition is "the degree of the choices people make and the degree of effort they will exert" (Keller, 1983). Because learning is an active process which requires conscious and deliberate activity, it is closely related to motivation. For students who want to derive maximum benefits from school, educators must create a learning environment in which students are deeply motivated to engage both actively and productively in learning activities (Stipek, 2002). If we take culture into consideration, a useful functional definition of motivation is to understand it as "a natural human process for directing energy to accomplish a goal" (Wlodkowski, 1999).

Many researches have revealed that there is a close relationship between learning motivation and cultural factors. Based on a survey on students in Japan who are educated in a score-oriented culture, Wilson's study (2001) reveals that "the premium on academic success in rote-learning educational model is perceived to be inimical to the development of attitudes to learning". Graham (2001) conducted a program of research on achievement patterns of African American ethnic minority youth and found out complex Ethnicity *Gender* Age interactions when studying achievement values. Hong (2001)'s research showed that the effort attribution emphasized in Chinese culture didn't necessarily render Chinese students more motivated in learning and less vulnerable to helpless achievement patterns in comparison with their western counterparts.

\subsubsection{Theoretical Framework of Motivation}

The theoretical framework of motivation in this study includes relevance, interest, affect, reinforcement, self-efficacy and learner control. To specify motivation types valid for online learning, a thorough investigation of learning motivation theory and instrument was conducted.

Relevance. John Keller, based on existing researches on psychological motivation, created the ARCS model (Keller, 1987). In his theory, Keller (1987) contends that attention and motivation will not be maintained unless the learner believes the teaching and learning is relevant.

Interest. Interest can be described as "a psychological state that involves focused attention, increased cognitive functioning, persistence, and emotional involvement" (Hidi, 2000). The level of interest a student brings to a subject or activity has been shown to affect intrinsic motivation for that task. According to Malone's theory (1981), a high interest in a subject can lead to mastery goals and intrinsic motivation.

Affect \& emotion. Education is a complicated human behavior. It is hard to be measured directly by linear or quantitative methods, because there are affect and emotion among learning and teaching process. Affect, as an intrinsic motivator, is a state of emotional feelings, concerns and passions of individual learner while learning (Wlodkowski, 1999).

Reinforcement. Skinner's theory lays the emphasis on the role of reinforcement in learning. Following Skinner's lead, there are many techniques of behavior modification. Students are motivated to complete a task by being promised a reward of some kind. From the behavioral view of motivation, reinforcement inspired behavior.

Self-efficacy. It refers to an individual's estimate or personal judgment of his or her own ability to succeed in reaching a general or specific goal. Maslow (1987) describes need hierarchy of 5 levels. The first four needs (physiological, safety, belongingness and love, and esteem) are often referred to as deficiency needs because they motivate people to act only when they are not fully satisfied. Self-actualization is often called a growth need 
because people constantly strive to satisfy it. Basically, self-actualization refers to the need for self-fulfillment - the need to develop all of one's potential talents and capabilities.

Learner control. Learner control is another motivation factor which exerts influence on learner's behavior. Chung and Davis (1995) categorize learner control behaviors into four types: learner control of content, learner control of sequence, learner control of learning pace (time management); and learner control of instructional display. Researches have verified that learners are more motivated if they are allowed some control over their own learning. The critical variables that influence learner control decision are the experience of an individual learner and the importance of learning task (Chuang \& Davis, 1995).

\section{Methodology}

\subsection{Design}

This study is to identify whether online learners in China and in America perceive a different motivation to online learning. It is a causal-comparative one. The null hypothesis is that there is no difference in motivation between Chinese and American cultural background for online learning. The alternative hypothesis is that there is different motivation toward online learning by the different cultural background. The independent variable is culture issue as American and Chinese culture. The dependent variable is online learning motivation.

\subsection{Participants}

There were a total of 372 students who participated in this survey in the U.S and China. 265 of the participants were undergraduate students. There were a total of 162 American students and 210 Chinese students. For the reason of better comparison, international students in America, graduate students and online learners with web only experiences were excluded from the sample.

Included in this sample were 107 American students and 158 Chinese students. The American part of sample consisted of students from West Virginia University. The Chinese participants were students from Fudan University, Shanghai. They participated in this survey either by an online survey $(8.68 \%)$ or a paper and pencil questionnaire in classroom (91.32\%). The demographic information gathered indicates approximately $40.4 \%$ of the respondents are males, $59.6 \%$ females, $14 \%$ are married, $84.9 \%$ are single, and $1.1 \%$ are divorced. Of the respondents, $44.5 \%$ are employed full-time. While $27.5 \%$ are part-time employed, and $27.9 \%$ are not employed.

\subsection{Instrument}

There are several survey instruments of learning motivation used by educators and researchers. In 2003, Laszlo, Jr., Kupritz and Lim developed a modified instrument specifically meeting the identified needs of online learning motivation. It is based on the Instructional Material Motivation Survey (Keller, 1987) and the Motivated Strategies for Learning Questionnaire (Pintrich, Smith, Garcia, \& McKeachie, 1993). A pilot study was conducted to determine item correlation and reliability. Five items were rejected due to respondent misinterpretation or item duplication as determined by item correlation coefficients of $r<.70$. The final instrument consisted of 24 items using a Likert scale ranging from (1) "Strongly Disagree" to (5) "Strongly Agree". Each item was grouped into one of five key learning motives (Laszlo, Jr., Kupritz, \& Lim, 2003). The validity of these two surveys has been tested several times in this field. The reliability alpha for each category is as follows: Overall alpha (.92), Course relevancy (.96), Course interest (.74), Affect/emotion (.53), Reinforcement (.67), Self-efficacy (.83), Learner control (.86). The validity of this study was tested using expert review and correlational analysis from other online learning outcomes conducted in previous studies. In this study, there was a question asking how this survey accurately assesses participants' online learning motivation. And the mean is 3.96 with standard deviation of 0.669 .

With permission, this instrument was used to identify the cultural difference between Chinese and American students. There were 6 demographic questions asked in the beginning of the survey. Participants were asked about their online learning experiences, major, GPA, gender, education level, marital status and employment level. As a result, 32 questions were asked to measure online learners' motivation. Basic descriptive statistics were used to analyze the level of online learning motivation perceived by all students. A T-test was utilized to measure gender difference in the learning motivation. One-way analysis of variance was employed to verify the effect of student characteristics on the learning motivation.

\subsection{Tools}

In this study, the basic descriptive statistics was used to analyze the level of online learning motivation perceived by all students. SPSS 13.0 (Statistical Package for Social Sciences) was performed to analyze the data. T-tests and one-way ANOVAs were utilized to measure the cultural differences in learning motivation. Six motivation 
types (including relevance, interest, affect, reinforcement, self-efficacy and learner control) and the overall motivation were compared. An alpha level of .05 was used for all statistical tests.

\section{Results}

\subsection{Participant Profile}

Table 1 reports the demographic information of participants by country, which includes gender, education level, marital status, employment status, major and GPA.

Table 1. Demographic characteristic of respondents

\begin{tabular}{lccc}
\hline \multicolumn{1}{c}{ Characteristics } & Number (Percentage) & China (N=158) \\
\cline { 2 - 4 } Gender & Total (N=265) & U.S.A (N=107) & $36(22.8)$ \\
Male & $107(40.4)$ & $71(66.4)$ & $122(77.2)$ \\
Female & $158(59.6)$ & $36(33.6)$ & $158(100)$ \\
Education & & & $111(70.3)$ \\
Undergraduate & $265(100)$ & $107(100)$ & $22(13.9)$ \\
Employment status & $118(44.5)$ & $7(6.5)$ & $25(15.8)$ \\
Full-time & $73(27.6)$ & $51(47.7)$ & $18(1.4)$ \\
Part-time & $74(27.9)$ & $49(45.8)$ & $138(87.3)$ \\
Not employed & & $19(17.8)$ & $2(1.3)$ \\
Marital status & $37(14.0)$ & $87(81.3)$ & $1(0.9)$ \\
Married & $225(84.9)$ & & \\
Single & $3(1.1)$ & & \\
Divorced & & & \\
\hline
\end{tabular}

\subsection{National Differences}

Overall, a significant difference in average motivation score was observed between the two countries $(\mathrm{p}<0.05)$. Online students in the U.S. showed a significantly higher motivation mean score than those in China.

Table 2. Differences in motivation types between countries

\begin{tabular}{cccccc}
\hline Motivation Type & Mean (SD) & Country & $\mathrm{N}$ & Means for each country (SD) & T-test p-value \\
\hline Course relevance & $4.02(0.63)$ & US & 107 & $4.20(0.61)$ & 0.000 \\
& & CH & 158 & $3.90(0.61)$ & 0.230 \\
Course interest & $4.03(0.59)$ & US & 107 & $4.09(0.53)$ & 0.944 \\
Affect \& emotion & $3.56(0.70)$ & US & 107 & $3.00(0.62)$ & 0.004 \\
& & CH & 158 & $3.56(0.70)$ & $3.99(0.60)$ \\
Reinforcement & $3.86(0.62)$ & US & 107 & $3.77(0.61)$ & 0.003
\end{tabular}




\begin{tabular}{|c|c|c|c|c|c|}
\hline & & $\mathrm{CH}$ & 158 & $3.63(0.63)$ & \\
\hline \multirow[t]{2}{*}{ Learner Control } & $3.71(0.76)$ & US & 107 & $3.64(0.84)$ & 0.196 \\
\hline & & $\mathrm{CH}$ & 158 & $3.76(0.69)$ & \\
\hline \multirow[t]{2}{*}{ Overall motivation } & $3.82(0.47)$ & US & 107 & $3.89(0.44)$ & 0.039 \\
\hline & & $\mathrm{CH}$ & 158 & $3.77(0.48)$ & \\
\hline
\end{tabular}

Table 2 reports the mean scores of the six motivation types. Regarding the importance of each motivation type, course interest and course relevancy marked the highest mean scores followed by reinforcement, self-efficacy, affection and emotion, and learner control. When the six sub-categories of students' motivation mean scores were compared, the highest motivation for Chinese students was course interest followed by course relevance, reinforcement, learner control, self-efficacy, then affection and emotion. However, for American students, the highest motivation was course relevancy, followed by course interest, reinforcement, self-efficacy, learner control, affection and emotion.

To verify the difference in each motivation type between the U.S. and China, t-test was then conducted. Among the six motivation types, significant mean differences were found in course relevancy, reinforcement and self-efficacy, in which American students scored higher than Chinese students. There were only one motivation type Chinese students scored higher, that is learner control, which is usually considered not significant.

\subsection{Individual Level Differences}

To detect demographic differences, t-test was performed on gender issue.

Table 3. Gender differences in motivation types

\begin{tabular}{|c|c|c|c|c|}
\hline Motivation type & Gender & $\mathrm{N}$ & Means (SD) & T-test p-value \\
\hline \multirow[t]{2}{*}{ Course relevance } & Male & 107 & $4.14(0.57)$ & 0.01 \\
\hline & Female & 158 & $3.94(0.65)$ & \\
\hline \multirow[t]{2}{*}{ Course interest } & Male & 107 & $3.98(0.60)$ & 0.21 \\
\hline & Female & 158 & $4.07(0.57)$ & \\
\hline \multirow[t]{2}{*}{ Affect \& emotion } & Male & 107 & $3.47(0.71)$ & 0.09 \\
\hline & Female & 158 & $3.62(0.69)$ & \\
\hline \multirow[t]{2}{*}{ Reinforcement } & Male & 107 & $3.80(0.68)$ & 0.24 \\
\hline & Female & 158 & $3.90(0.58)$ & \\
\hline \multirow[t]{2}{*}{ Self-Efficacy } & Male & 107 & $3.79(0.63)$ & 0.19 \\
\hline & Female & 158 & $3.69(0.63)$ & \\
\hline \multirow[t]{2}{*}{ Learner Control } & Male & 107 & $3.60(0.82)$ & 0.05 \\
\hline & Female & 158 & $3.79(0.70)$ & \\
\hline \multirow[t]{2}{*}{ Overall motivation } & Male & 107 & $3.80(0.48)$ & 0.525 \\
\hline & Female & 158 & $3.83(0.46)$ & \\
\hline
\end{tabular}

As shown in Table 3, there was no significant difference in overall motivation of students in different genders. But it did show female students have significantly higher motivation mean score for emotion and learner control than male students. However, male students scored higher than female students in course relevance significantly.

To identify the influence of employment status (full time, part time, not employed) and marital status (single, married, divorced, widowed), one-way ANOVA was performed on marital and employ issues. The mean scores, their standard deviation and the p-value from the one-way ANOVA are listed in Table 4 and 5. 
Table 4. Effect of employment status on online learning motivation

\begin{tabular}{|c|c|c|c|c|}
\hline Motivation type & Employment status & $\mathrm{N}$ & Means (SD) & One-way ANOVA p-value \\
\hline \multirow[t]{3}{*}{ Course relevance } & Full time & 118 & $3.88(0.63)$ & 0.004 \\
\hline & Part time & 73 & $4.12(0.58)$ & \\
\hline & Not employed & 74 & $4.15(0.63)$ & \\
\hline \multirow[t]{3}{*}{ Course interest } & Full time & 118 & $3.97(0.62)$ & 0.250 \\
\hline & Part time & 73 & $4.04(0.62)$ & \\
\hline & Not employed & 74 & $4.12(0.49)$ & \\
\hline \multirow[t]{3}{*}{ Affect/emotion } & Full time & 118 & $3.54(0.68)$ & 0.239 \\
\hline & Part time & 73 & $3.48(0.76)$ & \\
\hline & Not employed & 74 & $3.67(0.67)$ & \\
\hline \multirow[t]{3}{*}{ Reinforcement } & Full time & 118 & $3.76(0.55)$ & 0.023 \\
\hline & Part time & 73 & $3.85(0.77)$ & \\
\hline & Not employed & 74 & $4.01(0.52)$ & \\
\hline \multirow[t]{3}{*}{ Self-efficacy } & Full time & 118 & $3.63(0.64)$ & 0.051 \\
\hline & Part time & 73 & $3.75(0.64)$ & \\
\hline & Not employed & 74 & $3,86(0.58)$ & \\
\hline \multirow[t]{3}{*}{ Learner control } & Full time & 118 & $3.73(0.71)$ & 0.013 \\
\hline & Part time & 73 & $3.52(0.88)$ & \\
\hline & Not employed & 74 & $3.88(0.66)$ & \\
\hline \multirow[t]{3}{*}{ Overall motivation } & Full time & 118 & $3.75(0.47)$ & 0.016 \\
\hline & Part time & 73 & $3.79(0.52)$ & \\
\hline & Not employed & 74 & $3.95(0.39)$ & \\
\hline
\end{tabular}

Regarding the influence of employment status, Table 4 showed that mean scores of overall motivation, course relevancy, reinforcement and learner control were significantly different. Then Post Hoc Tests was performed to identify the significant difference is between full time and part time, full time and not employed, or part time and not employed. Turkey HSD showed that there were significant differences for course relevancy between full time and part time, full time and not employed; for reinforcement, the significant difference was between full time and not employed; for self-efficacy, it was between full time and not employed, for learner control, it was between part time and not employed, and for the overall motivation, it was between full time and not employed.

Table 5. Effect of marital status on online learning motivation

\begin{tabular}{lllll}
\hline Motivation type & Employment status & $\mathrm{N}$ & Means (SD) & One-way \\
\hline \multirow{3}{*}{ Course relevance } & Married & 37 & $4.02(0.86)$ & 0.688 \\
& Single & 225 & $4.02(0.57)$ & $4.33(1.15)$ \\
Divorced & 3 & $3.98(0.71)$ & 0.448 \\
Course interest & Married & 37 & $4.04(0.56)$ & $4.42(1.01)$ \\
& Single & 225 & $3.42(0.87)$ & 0.031 \\
& Divorced & 3 & $3.57(0.67)$ &
\end{tabular}




\begin{tabular}{lllll}
\hline \multirow{2}{*}{ Reinforcement } & Married & 37 & $3.89(0.67)$ & 0.272 \\
& Single & 225 & $3.84(0.61)$ & \\
Divorced & 3 & $4.42(1.01)$ & 0.286 \\
Married & 37 & $3.84(0.73)$ & 0.719 \\
Learner control & Single & 225 & $3.70(0.61)$ & \\
& Divorced & 3 & $4.08(1.18)$ & $3.80(0.85)$ \\
Married & Single & 37 & $3.70(0.74)$ & 0.252 \\
Overall motivation & Divorced & 225 & $3.83(0.76)$ & $3.83(0.59)$ \\
& Married & 3 & $3.81(0.44)$ & \\
\hline
\end{tabular}

Table 5 reports the differences for marital status issue. From this one-way ANOVA, it was identified that mean scores of affect and emotion were significantly different among the students group with different marital status (single, married, and divorced). Because in this sample, there was no attendance widowed. So there are just three levels of marital status. Then Post Hoc Tests was performed to identify the significant difference is between single and married, or single and divorced, or married and divorced. Turkey HSD showed that there was a significant difference just between married and divorced $(\mathrm{p}=0.031)$. Others were not significant different.

\section{Conclusion}

One major finding of this study is that American students indicated significantly higher motivation scores for the overall motivation and three motivation types (course relevance, reinforcement and self-efficacy) than Chinese students. Chinese students scored higher only for learner control, which is not significant. This leads to a meaningful discussion on the influence of different cultural orientation on learner motivation. The three motivation types that American students scored significantly higher than Chinese students can be explained in this regard.

Regarding the factor of gender, this study finds that female students scored significantly higher in learner control $(\mathrm{p}=0.05)$ than male students. Furthermore, although female students also showed significantly higher score in affect and emotion ( $\mathrm{p}=0.09$ ), male students scored significantly higher in course relevance, which implies that different gender showed different strong motivation type.

As for the issue of employment status, there are few studies which include it as a contributing factor. The reason why it was taken into comparison in this study is that, since more and more full-time or part-time employees have joined the online learning trend, it is necessary to consider the effects of learners' employment status on their online learning motivation. It was found that people with different employment status differ in mean scores of overall motivation, course relevance, reinforcement and learner control. In detail, unemployed students scored significantly higher than full time employed students in overall motivation, course relevance, reinforcement, self-efficacy and learner control. For course relevance, part-time employed students scored significantly higher than full-time employed students as well. The conclusion is that full-time employed students inevitably have less motivation on learning. Therefore, different teaching strategies should be employed according to different characteristics of students.

As for the marital status, Turkey HSD showed that there was a significant difference just between married and divorced ( $\mathrm{p}=0.031$ ) in affect and emotion. Because there were just four divorced participants in this study, the divorced sample was too small to be solid. The mean of divorced people is 4.50, and the mean of married is 3.42. One possible explanation is that the divorced people might have a stronger state of emotional feelings, concerns and passions as an intrinsic motivator because they could concentrate more on learning other than family or other social issues. 


\section{Implications}

In this study, just as some previous studies have revealed (Laszlo \& Virginia, 2003; Lim, 2004), for both American students and Chinese students, course interest and course relevance received the strongest agreement as a learning motive. Therefore, for online education, course interest and course relevance should still remain as a guiding issue in the course design and offering.

Compared to previous studies of online learning, means of affect and emotion in this study were the lowest among the motivation types. Wlodknowski (1999) once stated an individual's affection is also influenced by organizational and individual factors like organizational culture and climate, opinions of co-workers and supervisors, attitude towards change, degrees of frustration, etc. In online learning settings, where there exist different organizational culture and climate factors, students might be less concerned about their peers' opinions and more concerned about maintaining a certain level of autonomy. Therefore, another suggestion for online courses instructors is that end-of-course evaluation surveys should be a bit more robust than mere exit surveys, because immediate reactions to the course and its instructor may not be truly indicative, and should be retrieved after certain period of time has passed.

\section{References}

Annual National Convention of the Association for Educational Communications and Technology (AECT). (n.d.). Anaheim, CA.

Asunka, S., Chae, H. S., Hughes, B., \& Natriello, G. (2009). Understanding Academic Information Seeking Habits through Analysis of Web Server Log Files: The Case of the Teachers College Library Website. Journal of Academic Librarianship, 35(1), 33-45. http://dx.doi.org/10.1016/j.acalib.2008.10.019

Benson, E. P. (2002). Online learning: A means to enhance professional development. Critical Care Nurse, 24, 60-63.

Carliner, S. (2004). An overview of online learning (2nd ed.). Armherst, MA: Human Resource Development Press.

Chung, J., \& Davis, I. K. (1995). An instructional theory for learner control: Revisited, Proceedings of the 1995.

Conrad, D. (2002). Deep in the hearts of learners: Insights into the nature of online community. Journal of Distance Education, 17(1), 1-19.

Hamilton-Pennell, C. (2002). Getting ahead by getting online. Library Journal, 127, 32-35.

Hidi, S. (2000). An interest researcher's perspective: The effects of extrinsic and intrinsic factors on motivation. In C. Sansome, \& J. M. Harackiewicz (Eds.), Intrinsic and Extrinsic Motivation: The Search for Optimal Motivation and Performance. NY: Academic Press. http://dx.doi.org/10.1016/B978-012619070-0/50033-7

Hiltz, S. R., \& Turoff, M. (2005). Education goes digital: The evolution of online learning and the revolution in higher education. Communications of the ACM, 48(10). http://dx.doi.org/10.1145/1089107.1089139

Hoic-Bozic, N., Mornar, V., \& Boticki, I. (2009). A Blended Learning Approach to Course Design and Implementation. IEEE Transactions on Education, 52(1), 19-30. http://dx.doi.org/10.1109/TE.2007.914945

Keller, J. M., \& Kopp, T. W. (1987). Application of the ARCS model to motivational design. In C. M. Reigeluth (Ed.), Instructional Theories in Action: Lessons Illustrating Selected Theories (pp. 289-320). New York: Lawrence Erlbaum.

Li, J. (2002). A cultural model of learning: Chinese "heart and mind for wanting to learn". Journal of Cross-cultural Psychology, 33, 248-269. http://dx.doi.org/10.1177/0022022102033003003

Lim, D. H. (2004). Cross culture differences in online learning motivation. Educational Media International, 41, 163-173. http://dx.doi.org/10.1080/09523980410001685784

Newby, T. J., Stepich, D. A., Lehman, J. D., \& Russell, J. D. (2000). Instructional technology for teaching and learning: Designing instruction, integrating computers, and using media. Upper Saddle River, NJ: Prentice-Hall.

Osguthorpe, R. T., \& Graham, C. R. (2003). Blended Learning Environments: Definitions and Directions. Quarterly Review of Distance Education, 4(3), 227-233.

Pintrich, P. R., Smith, D., Garcia, T., \& McKeachie, W. (1993). Reliability and predictive validity of the motivated strategies for learning questionnaire. Educational and psychological Measurement, 53, 801-813. http://dx.doi.org/10.1177/0013164493053003024 
Salili, F., Chiu, C. Y., \& Hong, Y. Y. (2001). Student motivation: The culture and context of learning. New York: Kluwer Academic/Plenum. http://dx.doi.org/10.1007/978-1-4615-1273-8

Stipek, D. (2002). Motivation to learn: Integrating theory and practice. Allyn \& Bacon, Boston.

Uhlig, G. E. (n.d.). The present and future of distance learning. Education, 122(4), 670-673.

Wilson, J. D. (2001). Lifelong learning in Japan-A lifeline for a "maturing" society? International Journal of Lifelong Education, 20, 297-313.

Wlodkowski, R. J. (1999). Enhancing adult motivation to learn: A comprehensive guide for teaching all adults. Jossey-Bass, San Francisco.

\section{Copyrights}

Copyright for this article is retained by the author, with first publication rights granted to the journal.

This is an open-access article distributed under the terms and conditions of the Creative Commons Attribution license (http://creativecommons.org/licenses/by/4.0/). 